\title{
The Relationships Between Self-Efficacy, Managerial Competency and Learning Orientation on Job Performance Among Leaders in Saudi Universities
}

\author{
Ahmed Mohammed Saleh Ba wazir ${ }^{*}$, Dr. Qais Ahmed Amaamari², Dr.Baligh Ali Hasan ${ }^{3}$ \\ * Faculty of Business \& Management, Limkokwing University of Creative Technology, Selangor, Malaysia. \\ ${ }^{2}$ Faculty of Business \& Management, Limkokwing University of Creative Technology, Selangor, Malaysia. \\ ${ }^{3}$ Faculty of Administrative \& Financial Science, Gulf University, Sanad, Bahrain.
}

\author{
Article Info \\ Article history: \\ Received 12 January 2019 \\ Received in revised form 10 February 2020 \\ Accepted 01 March 2020 \\ Published 01 April 2020
}

\begin{abstract}
A modern competitive environment demands organizations to struggle more in order to sustain growth and be successful. Leadership is the most crucial factor affecting the triumph or defeat of an organization. The meaning of leadership has changed a lot in the last ten years. Therefore, this study was to investigate the relationship between self-efficacy and job performance of the Saudi university's leaders. For this purpose, data has been collected from 25 universities and analyzed by Smart-PLS Structural educational modeling. Results showed that university leadership's work performance had been numerously thought about in it; further to this, it tended to the hypothetical space by combining enterprising leadership as a critical intervening parameter. Current investigation has additionally figured out how to measure the influence of dynamic conditions in the connection between the extrinsic and intrinsic factors.
\end{abstract}

Keywords: Job Performance, Self-Efficacy, Learning Orientation, Leaders, Managerial Competency, Saudi Universities

\section{Introduction}

A modern competitive environment demands organizations to struggle more in order to sustain growth and be successful. Leadership is the most crucial factor affecting the triumph or defeat of an organization. The meaning of leadership has changed a lot in the last ten years. However, there has not been an investigation into the importance of leadership in the realm of higher education. A university leader's job role is packed with vaguely structured activities, which are huge with intricate nature (Kezar \& Holcombe, 2017). In this context, the discussion and investigation have extended and raised many questions regarding leadership and its effectual role (Mesterova et al., 2015). Leadership ensures that an institution attains its targets and completes the expected outcome, which is a wide belief. With the complicated landscape of the $21 \mathrm{st}$ century, demand for credible, sincere, and growth-oriented leaders has risen tremendously. The problem of leaders now affects universities and colleges which are suffering in this crisis. As there is an increasing trust deficit in individuals to be leaders of Higher-Education positions. Moreover, the issues in education institutions such as violence and increasing cost of attending a college or university along with interpersonal misbehave are matters of concern (Alayoubi et al., 2020). However, a positive sign is there has been a drive-in changing the highereducation leadership with job stakes for better leaders who address the global problems in the higher-education industry (Black, 2015).

Higher education responsibilities have increased, as the anticipation for surpassing job performance and productivity is most anticipated. The main issue at both departmental and organizational levels in universities is now the leader's productivity (Kaltenbrunner, 2018; Alkadash, 2020). As a global rule of thumb, leadership also influences the overall university's performance. Besides, many studies are related to leadership and its role in higher education. Lately, the researchers have not adequately systematically ascertained the factors which define leadership's efficacy in these establishments. As a population group, broad studies have not been conducted and found in university leaders' literary research study. Comparatively, there is extensive research available for a study about the role of leadership in business and middle managers, in contrast to academic leaders and their performance in higher education is nearly void (Asrar-ulHaq \& Anwar, 2018). Regarding those educational institutions which are flourishing and their academic departments are renowned, very little is written and known about the leadership role in their success. Therefore, for improvement in universities' performance, the role of effective leadership should be built like a model (Hartinah et al., 2020). 
Past observational research has reported that competencies are correlated with job attainment and fulfillment. Lee et al. (2018) have argued that the attempt to realize the common relationships is not properly found in the research regarding competencies examined in isolation. In this perspective, the important link between job achievement and institutions' success has to be statistically proven to find a correlation with the batch of competencies. The Institutional literature remains a primary issue that there is a connection between institutional success and job achievement and managerial competencies; an uphill competitive environment obliges institutions for it (Ghulam \& Mousa, 2019; Lee et al., 2019).

A leader's self-effectiveness appears to be an aspiring design for insight into their conduct and stimulation; many studies unwrapped, there exist a certain connection with self-effectiveness of a leader and job achievement. Nonetheless, particularly in the higher education field, it still has not been contrarily studied. Additionally, investigation about leader's self-efficacy is in its nascent years. Furthermore, the research regarding University leader's job achievement and selfefficacy, especially in higher education in Saudi Arabia, is rare and partially understudied (Alshaikhmubarak et al., 2020).

Due to the very small number of studies, learning orientation still needs to be researched more. In the perspective of performance outcome, careful examination related to learning is sparse. Although it is accepted in global business that learning is important, research regarding learning orientation across borders and the exporting realm framework is few. In scholarly literature, learning orientation has received appreciable attention, but the use of learning orientation as a variable, particularly with job achievement, is lacking. Therefore, this study looks into the learning orientation variable as one of the qualitative parameters affecting the leaders' job performance governing the universities of Saudi Arabia.

Based on the above debate, with a concentration on their self-efficacy to make them confident in their abilities to take opportune and productive actions, management competencies to make them management-wise strong, in addition to their academic capabilities, and learning orientation to understand and learn the prevailing needs of markets, clients, and other stakeholders make an aligning blend of parameters to fuel the growth of achievements of higher education leaders (Hentschke et al., 2017).

\section{Literature Review}

\subsection{Managerial Competency and Job Performance}

Job achievement variables were nominated as 'competencies' by McClelland in 1971; he quoted that these are behavioral parameters that forecast job performance and attainment. Mitchelmore \& Rowley (2010) concluded that results of job achievements or triumph in a work field are affected by individuals' lifelong intrinsic traits, and these comprise the leading component in the research of competencies. According to some researchers, managers can lead an organization to success if they have some particular set of competencies (Al-Tahitah et al., 2018). The most important skills of leaders who are leading to successful job performance managerial are based on skills such as interpersonal skills, business skills, and interpersonal skills literary works cite (Alzgool, 2019). Managerial competencies term is often used by flourishing managers who are recognized to have competence in their relevant working field and in connection to rising productivity in their performance mission and the decisions.

In the measure of performance assessment and performance predictors, managerial competencies are being used predominantly. From the viewpoint of intensifying performance and forecasting performance, managerial competencies are extremely significant (Wang et al., 2020). Moreover, to gain significant advantage from intervention and prediction for enhancing managerial performance, managerial competencies can play a vital role. It is established that attainment of the firm's strategic goals depends on significant tools of human resources management dedicated for this purpose. Managerial competencies comprise behavior, which is integral to completing the indispensable level of a manager or leader's performance and achievement, in union with effective firm management and becoming a crucial factor of accomplishment and also for competitive superiority. Visser (2009) devised a framework for management competency for the growth and training of university leaders. This has been widely published in the literature review in the South African higher-education environment and concludes that competencies realize effective performance at work. However, in order to expand both individual and institutional performance, formal coaching of university leaders is necessary, further increasing their knowledge of competencies (Alzyoud et al., 2019). It has been observed that the accumulation of individual competencies and human resources has given a superior benefit to the institution's growth and success, and a large number of scholars have an affirmative opinion verifying the link between managerial competencies and job achievements. Based on this argument. The first hypothesis is devised as follows:

- H1: Managerial Competency significantly impacts the job performance of university leaders in Saudi Arabia.

\subsection{Self-Efficacy and Job Performance}

Bandura (1997) reexamined about two thousand published research infiltrating self-efficacy structure in a matrix of performance regions. As an example, thinking patterns about personal capabilities were recognized to affect scholarly achievements, decision making, entrepreneurship, job options, teaching performance, athletic functioning, drug, and alcohol refrain, tolerating stress, voter inclusion, and organizational operations. In the field of entrepreneurship, countless verifiable researchers have found a relation between achievements and a general gauge of self-efficacy to be related. 
When the managers elevated their performance anticipation and strengthened self-efficacy, their enhanced achievements determined them as leaders (Gure, 2017). Many researchers in the context of the organizational framework determine that enhancing performance requires vital self-efficacy. Albert Bandura \& Locke (2003) confirmed that the most vital variable in job achievements is self-efficacy.

The literature on leadership and self-efficacy concluded the general argument that the leader's firmer self-efficacy beliefs are directly proportional to leadership success (Carleton et al., 2018). It is believed that individuals with a raised level of self-efficacy about a given task definitely outperformed those with lesser beliefs. The individuals with deficiencies in self-efficacy about some particular job frequently even did not attempt those jobs. The research has constantly unleashed that even the link between self-efficacy and job performance exists; self-efficacy is a better variable, in contrast to past achievements or future performance. Research on the effects of self-efficacy determined that self-efficacy is the dominantly vital determinant of performance. Leaders with higher self-efficacy are more inclined to have an interest in the job, more willing to deploy their full potential, and display more convictions in difficult and unworthy situations (Alateyah, 2018).

As a result, these leaders perform better. In some educational work, it has been informed that an outstanding level of self-efficacy results in better performance. The affirmative link between achievements and self-efficacy has also been opined in several types of research (Chen, 2017). Two meta-analyses that were concluded on the relationship between self-efficacy and job performance unleashed corrected correlations of 0.38 and 0.23 , respectively, between job performance and self-efficacy(Stajkovic \& Luthans, 1998; Judge \& Bono, 2001). Cherian \& Jacob (2013) also conducted a meta-analysis that observed the individual research results related to the link between employee motivation, selfefficacy, and staff's job-related achievements. From the results of the research, it was observed that self-efficacy theory could be applied to job-related performance.

Researchers of different institutions widely researched efficacy constructs such as general efficacy, self-efficacy, forms of collaborative or group efficacy, and means efficacy. This body of research has reportedly shown how each of these forms of efficacy is related to required performance on a job. The magnitude of individuals with self-efficacy comprehended related surely with their previous performances and forces they have confidence that results in further outstanding performance(Özel, 2019). Olusola's (2011) investigation's results emphasized two things. The first concluded that job satisfaction, individual characteristic motivation, and self-efficacy forecast the job performance of promising employees. The second opined the idea that each of these traits forecasts employees' job performance.

Self-efficacy is always linked with performance as it influences the actions that individuals seek and how much effort they induct into those actions. Those people with higher self-efficacy set higher performance objectives and then originate more professionally perform job strategies than that low in self-efficacy (Trautner \& Schwinger, 2020). Based on the above discussion, the second hypothesis is devised as follows;

- H2: self-efficacy significantly has a positive impact on job performance.

\subsection{Learning Orientation and Job Performance}

Higher-order and lively learning is frequently recognized as a major variable of higher performance. This learning allows organizations to respond to variance and act expeditiously in complicated and disruptive business surroundings. Previous researches unwrapped that learning orientation indirectly correlated both gains through innovation and the institution's performance (Pramono et al., 2015). An organization that has the capability to understand speedily than its competitors will be on high performing and upkeep in the business (Alzyoud et al., 2019). For the small and medium organizations, learning orientation displayed an important positive affiliation with financial performance and was also correlated and considerably affiliated with non-financial performance. Small and medium enterprises with increased levels of learning orientation are interconnected with improved innovation and usually outperform their contestants with excellent performance (Mohammed \& Rugami, 2019). Until now, important literary works are primarily focused on the hypothetical ramifications in the field of learning orientation.

In any case, learning orientation association to various proportions of work achievements has explored and surveyed by scholars, and these inquiries, have approved quite an extent, affirmative relations between learning orientation and job performance (DeMarsay, 2020). Likewise, research outcomes ascertained that learning orientation has a significant impact on broad advancement and work performance improvement. Typically, organizations with larger amounts of direction focused on learning exhibit higher success ratios than firms with a lower learning orientation dimension, demonstrating the link between learning orientation to work performance. Primarily, it is correct for competition supportive and robust workplaces. It is uncovered from past investigations that learning orientation is connected with just as it improves the institution's development process and success. Based on the discussion above regarding writing, the third theory is presented.

- H3: learning orientation significantly has a positive impact on the job performance of university leaders in Saudi Arabia 


\section{Conceptual Framework of the Study}

This particular study's proposed model is composed of three independent variables; managerial competencies, selfefficacy, and learning orientation; which have a direct impact on the dependent variable, job performance.

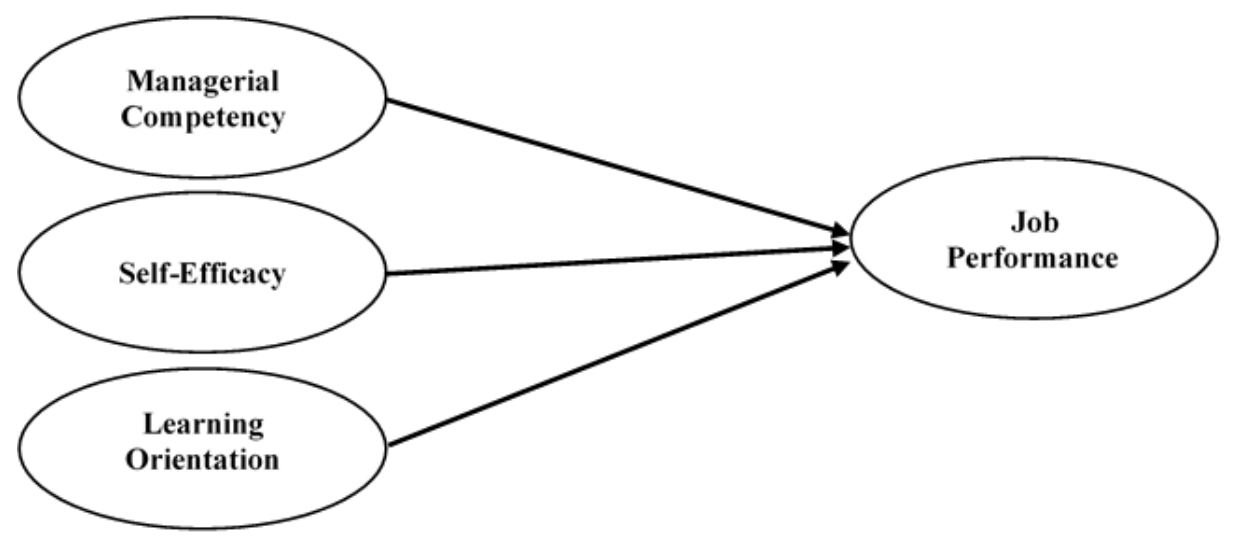

Fig. 1. Conceptual Framework of Research

\section{Research Methodology}

\subsection{Technique and measurement}

The intention of this examination is to explore the connections between impartial parameters such as (management competency, self- productiveness, and learning orientation) to a reliant variable (performance at work). The unit of investigation for this examination is the leadership of universities in 25 states owned higher education institutions of Saudi Arabia. The participant's frame of mind towards their work performance is estimated just as their discernments towards the impact of their competent skills in management, self-adequacy, learning orientation, innovative authority, and dynamic conditions of their work performance. For examining random sampling, design configuration was utilized for its effortlessness, more affordable, and simpler to oversee.

\subsection{Data Analysis}

The study utilized PLS-SEM approach for data analysis. This technique is known as second-generation structural equation modeling (Wold, 1982). As a relatively new method, it functions admirably with structural equation models that incorporate a progression of circumstances and logical results, connections, and dormant factors (Gustafsson and Johnson, 2004). Divided into two phases, the main stage assesses accuracy, and dependability is researched known as measurement model evaluation, whereas in the second-stage, hypotheses are tried.

\subsection{Measurement Model}

In this section, content validity, convergent validity, and distinguishing validity will be debated under the head of construct validity.

Table 1. Factor loading

\begin{tabular}{|c|c|c|c|}
\hline Construct Items & Loadings & AVE & CR \\
\hline \multicolumn{4}{|c|}{ Managerial Competency } \\
\hline MC1 & 0.789 & 0.512 & 0.862 \\
\hline MC10 & 0.661 & & \\
\hline MC2 & 0.699 & & \\
\hline MC3 & 0.773 & & \\
\hline MC4 & 0.630 & & \\
\hline MC5 & 0.726 & & \\
\hline \multicolumn{4}{|l|}{ Job Performance } \\
\hline PF1 & 0.780 & 0.513 & 0.894 \\
\hline
\end{tabular}




\begin{tabular}{|c|c|c|c|}
\hline Construct Items & Loadings & AVE & CR \\
\hline PF17 & 0.695 & & \\
\hline PF18 & 0.702 & & \\
\hline PF19 & 0.713 & & \\
\hline PF2 & 0.769 & & \\
\hline PF20 & 0.698 & & \\
\hline PF22 & 0.666 & & \\
\hline PF4 & 0.701 & & \\
\hline \multicolumn{4}{|l|}{ Self-Efficacy } \\
\hline SE1 & 0.852 & 0.570 & 0.888 \\
\hline SE2 & 0.818 & & \\
\hline SE3 & 0.740 & & \\
\hline SE4 & 0.674 & & \\
\hline SE5 & 0.733 & & \\
\hline SE7 & 0.697 & & \\
\hline \multicolumn{4}{|c|}{ Learning Orientation } \\
\hline LO1 & 0.782 & 0.510 & 0.892 \\
\hline LO11 & 0.660 & & \\
\hline LO2 & 0.731 & & \\
\hline LO3 & 0.733 & & \\
\hline LO4 & 0.700 & & \\
\hline LO6 & 0.810 & & \\
\hline LO1 & 0.782 & 0.510 & 0.892 \\
\hline LO11 & 0.660 & & \\
\hline LO2 & 0.731 & & \\
\hline LO7 & 0.638 & & \\
\hline LO8 & 0.640 & & \\
\hline
\end{tabular}

\section{Discriminant validity}

Table 2 shows the outcomes of the discriminant validity evaluation of the variables used in this study. Along the diagonal, the table presents AVE's square roots for all the constructs indicating higher square roots of AVE; all the square roots of AVE for the constructs are bigger than the off-diagonal elements or coefficients in the corresponding columns and rows, hence, establishing evidence of discriminant validity.

Table 2. Discriminant Validity

\begin{tabular}{lllll}
\hline Construct & LO & MC & PF & SE \\
\hline Learning Orientation (LO) & $\mathbf{0 . 7 1 4}$ & & & \\
Managerial Competency (MC) & 0.344 & $\mathbf{0 . 7 1 5}$ & & \\
Job Performance (PF) & 0.308 & 0.579 & $\mathbf{0 . 7 1 6}$ & $\mathbf{0 . 7 5 5}$ \\
Self-Efficacy (SE) & 0.346 & 0.422 & 0.312 & \\
\hline
\end{tabular}

This table presented the results of the measurement model for this study, which indicated that the measures for all the constructs are reliable and valid; the next step is to present the structural model results. 


\subsection{Structural Model}

The following section shows the consequences of the structural model and the trial of hypotheses for the research. In particular, the segment is related to the testing of the hypotheses. SEM PLS structural model analysis was executed to comprehend the primary relationship impact inside the constructs. The values inside the PS structural model, displayed by standardized beta values, explore the contribution of every extrinsic factor (Chin, 1998). Likewise, the current examination connected the standard bootstrapping system with various 5000 bootstrap tests of 242 cases to evaluate the criticalness of the path coefficients. For the examination of the structural model relationships, the selection of significance level was set at $\mathrm{p}<.05$ and $\mathrm{p}<.01$ (Hair Jr et al., 2016).

Table 3. Results of Main Effects Hypotheses

\begin{tabular}{llllll}
\hline Hypothesis & Relationship & Std Beta & Std Error & T-Value & Decision \\
\hline $\mathrm{H} 1$ & $\mathrm{MC} \rightarrow \mathrm{PF}$ & 0.298 & 0.079 & $3.793^{* *}$ & Supported \\
$\mathrm{H} 2$ & $\mathrm{SE} \rightarrow \mathrm{PF}$ & 0.423 & 0.072 & $5.901^{* *}$ & Supported \\
$\mathrm{H} 3$ & $\mathrm{LO} \rightarrow \mathrm{PF}$ & 0.187 & 0.057 & $3.282^{* *}$ & Supported \\
\hline
\end{tabular}

Hypothesis 1 forecasted an effect of competencies in management on the job performance of university leaders. Results (Table 4.13, Figure 4.2) unleashed an important positive effect of competencies in management on job performance $(\beta=$ $0.298, \mathrm{t}=3.793)$, thus supporting the hypothesis. Hypothesis 2 forecasted an effect of self-efficacy on the job performance of university leaders. Results (Table 4.13, Figure 4.2) represented an important positive effect of self-efficacy on job performance $(\beta=0.423, t=5.901)$, thus supporting Hypothesis 2 . Similarly, Hypothesis 3 forecasted an effect of learning orientation on the leadership of universities' job performance. Results concluded a significant positive effect of learning orientation on job performance $(\beta=0.187, \mathrm{t}=3.282)$, which also supports Hypothesis 3 .

\section{Discussion}

Management and leadership are the most key factors needed for any enterprise to succeed. Both processes are needed for an institution's performance. In the research and vast area of management writings, it is valued that it is not helpful to detach management from leadership and that both must endorse one another (Al-Harethi \& Al-Maamari, 2018). Brown \& Duguid (2001) advised that winning leaders should develop governance and manifestation in their goals and initiatives in order to educate their institutions. If that is the case, critical thinking is obtained at certain points and must be devised with modern competencies, vital knowledge, and skills in advancement with modern development in order to cope with present and diverse requirements. Notwithstanding some differences within themselves, two methods cannot function effectively without each other. An efficient performance goal necessitates a sustained transition of hats or hand-off, which will prove effective in a single boss/head environment. Leader generates the manager's notion of adaptation and interpretation, and his goal is to operate how to get there with regard to the essential care route. He can receive and distribute the necessary resources required by this action. According to university leaders ' choice, it is compulsory to match the new demand for management skills. Important fundamental designs of management skills in literary works replicate leadership qualities; interpersonal skills; business acumen, and communication skills as essential to productive managerial success. Whiddett \& Hollyforde (2003) characterized management competencies as specialized skills, knowledge, and traits shown by individual people in the rewarding implementation of functions inside the organization. Hypothesis H1 of this study defines that there is an important connection between management competencies and performance at work of university leadership in Yemen. Reliability Analysis

Results showed in the previous chapter found support for the first hypothesis, H1.

0.01 level of significance $(\beta=0.768, t=21.989, p<0.01)$. The outcome means that managerial competency was examined to be an important variable of university leaders' job productivity.

Findings also coincide with the theory of social cognitive learning, which suggests a thorough correlational structure that addresses the development of individual competencies and their impact on the oversight of their behavior patterns (performance). Mechanisms of knowledge (competence) signifying effective action techniques, rules, and models represent as behavioral guides for constructing challenging behavior patterns (performance). Because they would be able to perform better through their skills, this is applicable to a large extent under the university leadership. This study's body of knowledge is expanded by explaining the connection between variables such as management competencies and university leadership's productivity.

Strong belief in self- adequacy and abilities will reinforce the efforts to overcome the challenge when faced with difficulties and obstacles; this quality is linked with self-efficacy in the environment of leadership, suggested by Albert Bandura (2001). The final outcomes achieved by the individual are dependent upon the beliefs in self-efficacy, which are 
robust factors and variables are determining the level of success attainable. Effective leaders in the education sector are those determined to pursue goals. It is the quality of effective leaders; they reckon failures with missing effort or dysfunctional strategy instead of blaming lack of capacity when tackling problems. By applying the best strategies and amplifying the efforts, the goals are achieved, and victory is attained by leaders who are strong believers of self-efficacy. It is found in the theoretical studies on self-efficacy that the amount of energy given to a task and longer perseverance in the face of obstacles and difficulties; self-efficacy influences the goals that people choose. Skills that are suitable to perform intelligently to execute a job increase when believing in self-efficacy amplifies belief in self and self-reliance (Muwonge et al., 2017). The H2 study hypothesis asserts that there is a link between Saudi Arabia's universities' leadership with their self-efficacy and performance at work. Outcomes presented in previous chapter concluded support for the second hypothesis at the 0.01 level of significance $(\beta=0.768, t=21.989, p<0.01)$. The result means that selfefficacy was determined to be the important factor of productivity of leadership of universities.

It was also duly noted that the leadership roles in the higher education positions required them to cope with all the difficulties and react to overcome these problems presented by different pressures and hurdles from many diverse sources; some of them are realistic, but some of these are also only staged. With high self-efficacy, these pressures induced them, and they showed great attempts to address these obstacles. They thus demonstrate efficiency and effectiveness through their heightened self-efficacy. Hassan et al., (2015) also revealed that individuals' obstacles often inspire superior efforts with enhanced self-efficacy. Higher-education institutions often employ leadership with a proven record of successes, or on the grounds of their previous achievements, individuals retained those jobs. Upon reaching the important job positions, they also have the faith and trust they have in demonstrating themselves with more solid performances from their past achievements. It is shown by Holzberger et al. (2013) and Valiante \& Morris (2013) that previous achievements transmit the self-belief that impacts more outstanding growth and productivity. The theory of social cognitive learning is suggested through the mechanistic framework, and the outcomes are also congruent with this; it looks at the development of people's self-efficacy and its impact on their conduct (productivity) oversight. By means of two mediating processes, self-efficacy beliefs impact results: task approach creation and determination of a person. An important behavioral framework of selfdirectedness and determination is the readiness to exercise personality-influence according to one's contest through analytical response and targeting goals to enhance an individual's productivity. Relating this more to the university leaders as they can function better in the highly volatile atmosphere in the face of overwhelming chaos across their self- efficacy ideals. Adding value to the body of knowledge, this research further expands and explains the connection between university leaders ' self-efficacy and professional success.

The acceptance of the third proposed hypothesis that performance of university leadership is heavily influenced by learning orientation, supported by results concluded in the previous chapter by looking at the value of significance 0.01 level of significance $(\beta=0.768, \mathrm{t}=21.989, \mathrm{p}<0.01$. Cognitive learning theory, which suggests the impact of comprehensive learning structure for growth in individual learning and its impact on their behavior (performance), is also proven to be consistent according to proposed results. The emphasis of psychological theories remains centered on learning through influences on behavior, organizations of their work, or social networks. This basic learning directly influences leader's performance and their actions. It is fundamental learning, which enables a university leader to perform better than others in a chaotic and highly changing environment. This study's major impact is an improved understanding of the relationship between learning orientation and performance at work for university leaders.

\section{Conclusions}

As a whole, the current research has given extra proof to the developing accumulation of knowledge concerned with outcomes from this investigation, extending to the key hypothetical recommendations. Specifically, the investigation has effectively addressed the majority of the study's questions and goals regardless of a few of its restrictions. University leadership's work performance has been numerously thought about in other studies; the present study tended to the hypothetical space by combining enterprising leadership as a critical intervening parameter. Current investigation has also figured out how to measure dynamic conditions' influence in the connection between the extrinsic and intrinsic factors. Future investigations have been given directions to follow through the discoveries made ready.

This examination's outcomes have given some significant functional ramifications to institutions, policymakers, stakeholders, and management, besides the theoretical input. Numerous future studies' directions were drawn in current research, besides some limitations. All in all, the present examination has contributed important hypothetical, functional, and methodological repercussions to the growing group of information in the field of university leaders, work performance estimation and improvement, organization enterprise and management, management abilities, self-viability, and learning orientation, especially in the university education segment.

It has been prescribed for present-day higher education institutions, unsurprisingly, that an ability to create leadership pioneers who oversee intricacy, cooperating effectively, including individuals in the vision, and driving through change is not an extravagance but rather a key need' (Abdulrab et al., 2017). 


\section{References}

Abdulrab, M., Zumrah, A. R., Almaamari, Q., \& Altahitah, A. (2017). The role of psychological empowerment on work engagement: The development of conceptual framework. International Journal of Business Management and Economic Research, 8(6), 1157-1163.

Al-Harethi, A. A. M., \& Al-Maamari, Q. A. (2018). The Impact of Strategic Planning on Improving Institutional Performance at Limkokwing University of Creative Technology in Malaysia. International Journal of Psychology and Cognitive Science, 4(3), 112-129.

Al-Tahitah, A., Muthaliff, M. M. A., Abdulrab, M., \& Al-Maamari, Q. A. (2018). Paper Review on the Relationship Between Transformational Leadership and Readiness for Change. International Journal of Energy Policy and Management, 3(1), 1-7.

Alateyah, S. (2018). The Determinants of E-recruitment and its effect on HRM Capabilities and the Firm's Performance: Evidence from Saudi Arabia Context. University of Plymouth.

Alayoubi, M. M., Al Shobaki, M. J., \& Abu-Naser, S. S. (2020). Strategic Leadership Practices and their Relationship to Improving the Quality of Educational Service in Palestinian Universities. International Journal of Business Marketing and Management (IJBMM), 5(3), 11-26.

Alkadash, T. (2020). Mediating Role between Authentic Leadership, Organizational Commitment on Talents Turnover Intention: in Palestine Higher Education. TEST Engineering \& Management, 83, 5320-5341.

Alshaikhmubarak, A., Da Camara, N., \& Baruch, Y. (2020). The impact of high-performance human resource practices on the research performance and career success of academics in Saudi Arabia. Career Development International.

Alzgool, M. (2019). Nexus between green HRM and green management towards fostering green values. Management Science Letters, 9(12), 20732082.

Alzyoud, A. A. Y., Ahmed, U., AlZgool, M. R. H., \& Pahi, M. H. (2019). Leaders' emotional intelligence and employee retention: Mediation of job satisfaction in the hospitality industry. International Journal of Financial Research, 10(3), 1-10.

Asrar-ul-Haq, M., \& Anwar, S. (2018). The many faces of leadership: Proposing research agenda through a review of literature. Future Business Journal, 4(2), 179-188.

Bandura, A. (1997). Self-efficacy: The Exercise of Control.

Bandura, Albert. (2001). Social cognitive theory: An agentic perspective. Annual Review of Psychology, 52(1), 1-26.

Bandura, Albert, \& Locke, E. A. (2003). Negative self-efficacy and goal effects revisited. Journal of Applied Psychology, 88(1), 87.

Black, S. A. (2015). Qualities of effective leadership in higher education. Open Journal of Leadership, 4(02), 54.

Brown, J. S., \& Duguid, P. (2001). Knowledge and organization: A social-practice perspective. Organization Science, 12(2), 198-213.

Carleton, E. L., Barling, J., \& Trivisonno, M. (2018). Leaders' trait mindfulness and transformational leadership: The mediating roles of leaders' positive affect and leadership self-efficacy. Canadian Journal of Behavioural Science/Revue Canadienne Des Sciences Du Comportement, 50(3), 185.

Chen, I.-S. (2017). Computer self-efficacy, learning performance, and the mediating role of learning engagement. Computers in Human Behavior, 72 , $362-370$.

Cherian, J., \& Jacob, J. (2013). Impact of self efficacy on motivation and performance of employees.

Chin, W. W. (1998). The partial least squares approach to structural equation modeling. Modern Methods for Business Research, 295(2), 295-336.

DeMarsay, T. A. (2020). A Qualitative Study Exploring the Lived Experience of Organizational Leaders with a Contemplative Practice. Fielding Graduate University.

Ghulam, Y., \& Mousa, W. I. (2019). Estimation of productivity growth in the Saudi higher education sector. Technological Forecasting and Social Change, 149, 119741

Gure, G. S. (2017). Gender Influences on the Entrepreneurial Tendencies \& Entrepreneurial Attitude of University Students. International Journal of Research in Social Sciences, 7(8), 746-759.

Hair Jr, J. F., Hult, G. T. M., Ringle, C., \& Sarstedt, M. (2016). A primer on partial least squares structural equation modeling (PLS-SEM). Sage Publications.

Hartinah, S., Suharso, P., Umam, R., Syazali, M., Lestari, B., Roslina, R., \& Jermsittiparsert, K. (2020). Retracted: Teacher's performance management: The role of principal's leadership, work environment and motivation in Tegal City, Indonesia. Management Science Letters, 10(1), $235-246$.

Hassan, A. E. H., Alasmari, A., \& Ahmed, E. Y. E. (2015). INFLUENCES OF SELF-EFFICACY AS PREDICTORS OF ACADEMIC ACHIEVEMENT. International Journal of Education and Research, 3(3), 275-284.

Hentschke, G. C., Parthenon-EY, E., Young, L. L. P., Jacobs, B. C., Jacobs, L. A., \& Ladd, H. (2017). Mergers in Higher Education: A proactive strategy to a better future? New York: TIAA Institute.

Holzberger, D., Philipp, A., \& Kunter, M. (2013). How teachers' self-efficacy is related to instructional quality: A longitudinal analysis. Journal of Educational Psychology, 105(3), 774

Judge, T. A., \& Bono, J. E. (2001). Relationship of core self-evaluations traits—self-esteem, generalized self-efficacy, locus of control, and emotional stability - with job satisfaction and job performance: A meta-analysis. Journal of Applied Psychology, 86(1), 80.

Kaltenbrunner, W. (2018). Situated Knowledge Production, International Impact: Changing Publishing Practices in a German Engineering Department. Minerva, 56(3), 283-303.

Kezar, A. J., \& Holcombe, E. M. (2017). Shared leadership in higher education. Washington, DC: American Council on Education.

Lee, A., Willis, S., \& Tian, A. W. (2018). Empowering leadership: A meta-analytic examination of incremental contribution, mediation, and moderation. Journal of Organizational Behavior, 39(3), 306-325.

Lee, H., Ahmed, U., Zhussupova, B., \& Khalid, N. (2019). Impact of innovation capability and competitiveness on entrepreneurial orientation regarding to the entrepreneurial education in business performance among South Korean firms. Polish Journal of Management Studies, 20.

McClelland, D. C. (1971). Assessing human motivation. NY.

Mesterova, J., Procházka, J., Vaculík, M., \& Smutny, P. (2015). Relationship between self-efficacy, transformational leadership and leader effectiveness. Journal of Advanced Management Science, 3(2).

Mitchelmore, S., \& Rowley, J. (2010). Entrepreneurial competencies: a literature review and development agenda. International Journal of Entrepreneurial Behavior \& Research.

Mohammed, R. A., \& Rugami, J. (2019). Competitive Strategic Management Practices and Performance of Small and Medium Enterprises in Kenya: A Case of Mombasa County. International Journal of Current Aspects, 3(VI), 193-215.

Muwonge, C. M., Schiefele, U., Ssenyonga, J., \& Kibedi, H. (2017). Determinants of persistence among science teacher-trainees: Examining the role of self-efficacy, task value, and academic hope. Journal of Science Teacher Education, 28(6), 522-548.

Olusola, O. (2011). INTINSIC MOTIVATION, JOB SATISFACTION AND SELF-EFFICACY AS PREDICTORS OF JOB PERFORMANCE OF INDUSTRIAL WORKERS IN IJEBU ZONE OF OGUN STATE. Journal of International Social Research, 4(17).

Özel, K. (2019). The Relationship between Emotional Intelligence, Social Intelligence and Self-Efficacy Among Preservice English Teachers. Eğitim Bilimleri Enstitüsü.

Pramono, R. B., Nimran, U., \& Utami, H. N. (2015). The influence of market orientation and learning orientation on performance through competitive advantage: An empirical study on combined farmer groups of the tidal area in south sumatera province. European Journal of Business and Management, 7(10), 232-239.

Stajkovic, A. D., \& Luthans, F. (1998). Self-efficacy and work-related performance: A meta-analysis. Psychological Bulletin, 124(2), 240.

Trautner, M., \& Schwinger, M. (2020). Integrating the concepts self-efficacy and motivation regulation: How do self-efficacy beliefs for motivation regulation influence self-regulatory success? Learning and Individual Differences, 80, 101890 .

Valiante, G., \& Morris, D. B. (2013). The sources and maintenance of professional golfers' self-efficacy beliefs. The Sport Psychologist, 27(2), 130- 
142.

Visser, I. L. (2009). Development of a proposed management competency training framework. Unpublished Master's Dissertation, University of Pretoria, Pretoria, South Africa.

Wang, T., Wu, J., Gu, J., \& Hu, L. (2020). Impact of open innovation on organizational performance in different conflict management styles: based on resource dependence theory. International Journal of Conflict Management.

Whiddett, S., \& Hollyforde, S. (2003). A practical guide to competencies: how to enhance individual and organisational performance. CIPD Publishing. Wold, H. (1982). Soft modeling: the basic design and some extensions. Systems under Indirect Observation, 2, 343. 